\title{
A three-bladed dilator for trans-ventricular mitral valvotomy
}

\author{
IAN MONK AND RUSSEL VANDENBERG ${ }^{1}$
}

From the Thoracic Unit and Cardiac Clinic, the Royal North Shore Hospital of Sydney

Since Andrew Logan first described the use of an expanding dilator introduced through the left ventricle for the relief of mitral stenosis this method has been widely accepted. The underlying principle is to use a two-bladed dilator, guided into and opened in the stenosed mitral valve, exerting a disruptive force causing separation of the fused commissures of the valve leaflets. This disruptive force must be exerted in two planes only, so that there is at least the theoretical possibility of tearing a valve cusp. In a small personal series of cases, therefore, a three-bladed dilator, together with the index finger used as a fourth dilating agent, has been used since December 1958 .

\section{THE METHOD}

Through a postero-lateral or antero-lateral thoracotomy the mitral valve is explored with the right index finger. If the stenosis cannot be relieved with the finger, then the finger is kept in the left atrium and a Brock three-bladed aortic valve dilator is used. The finger in the left atrium is passed down towards the apex of the left ventricle, and the tip of the dilator is inserted through the left ventricular wall onto the index finger. No controlling or purse-string suture has been used in the left ventricle in this series until the valvotomy has been completed. In this way the dilator is guided into the mitral valve orifice and damage to chordal or papillary structures is avoided. The blades of the dilator are then opened in the mitral orifice (see Figs 1 and 2). This usually separates one or other commissure, the maximum diameter of the dilator being $3.4 \mathrm{~cm}$. If it is judged that further separation of the fused commissures is necessary, then the dilator which has been kept in the left atrium is opened up again in the valve orifice, the index finger having been placed through the mitral valve alongside the dilator. The expanding force acting on the valve is thus exerted in four directions, i.e., three blades of the dilator plus the index finger. The diameter of the three blades of the dilator together

1 Roche Research Fellow of the Royal Australasian College of Physicians with the distal phalanx of the finger is $4.5 \mathrm{~cm}$. If the middle phalanx of the index finger is used it is $5 \mathrm{~cm}$. (Figs 3 and 4). Thus the final maximal dilating force is obtained by advancing the index finger through the valve beside the blades of the dilator. The finger often lies best on the medial side of the dilator, and the index finger is frequently the final force that separates the medial commissure.

\section{RESULTS}

Thirty-two patients were operated on using this method and they have been observed from six months to four years. Two-thirds of these were women and the average age was 45 years. There were 10 patients over the age of 50 and two patients were more than 60 years of age. The disability of the patients has been classified by the non-surgical author in accordance with the recommendations of the New York Heart Association. Thus 24 were classified as grade $3 \mathrm{~B}$ and the remaining eight as grade $3 \mathrm{~A}$. Of the 24 grade $3 \mathrm{~B}$ patients, two died soon after operation, leaving 22 grade $3 \mathrm{~B}$ patients for review. When seen at the first visit after discharge from hospital about six weeks after operation, 12 were classified as grade $3 \mathrm{~A}$, eight as grade 2 , and two patients as grade 1 . When reviewed again from six months to three years after operation, 11 were classified as grade $3 \mathrm{~A}$, eight as grade 2 , and three as grade 1 . Thus half of the grade $3 \mathrm{~B}$ cases were improved by two grades (Table I). Of the eight grade $3 \mathrm{~A}$ cases, all were improved by at least one grade and half were improved by two grades (Table II).

There were two deaths in this series. One patient was a man aged 58 with pulmonary hypertension of severe degree, moderate mitral incompetence with a grade 2 systolic murmur, and a moderately enlarged heart with well-marked calcification of the mitral valve. Congested lung fields were noted in the radiograph and the patient had grade 1 cyanosis. At operation a small mitral incompetent jet was felt up to $2 \mathrm{~cm}$. behind the valve. A satis- 


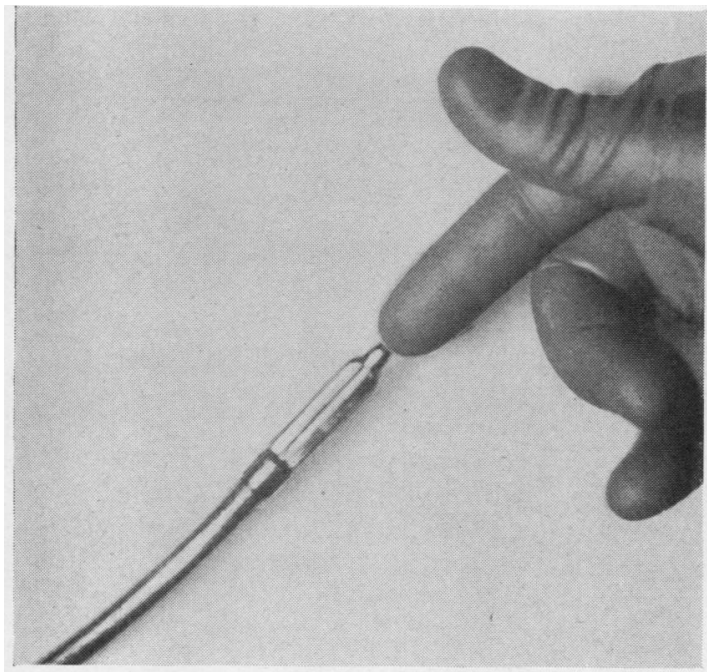

FIG. 1. Finger-tip guiding dilator.

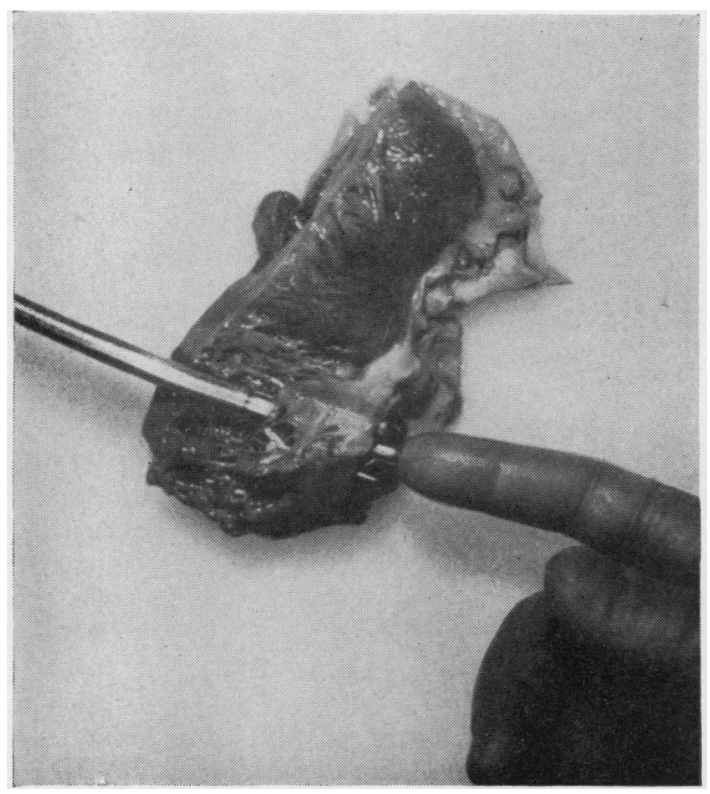

FIG. 2. Post-mortem heart with opened dilator which has been guided into the mitral valve.

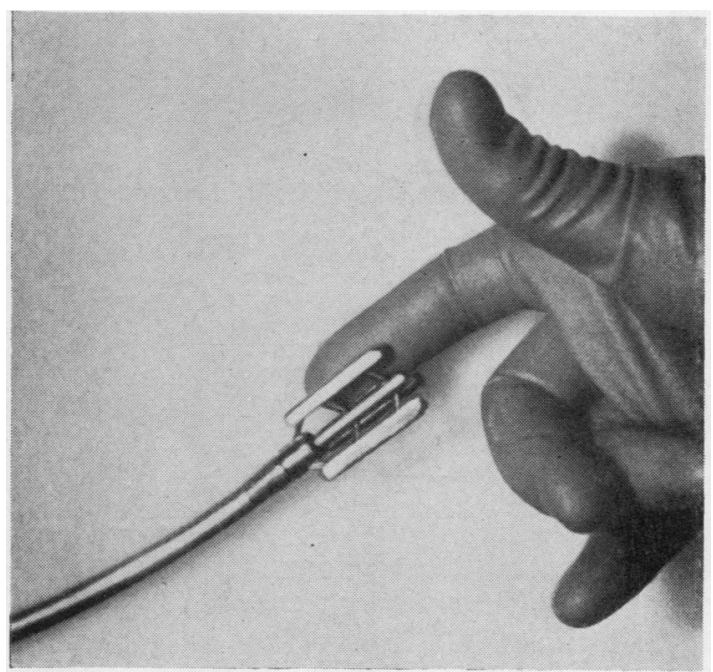

FIG. 3. The index finger placed alongside the opened dilator.

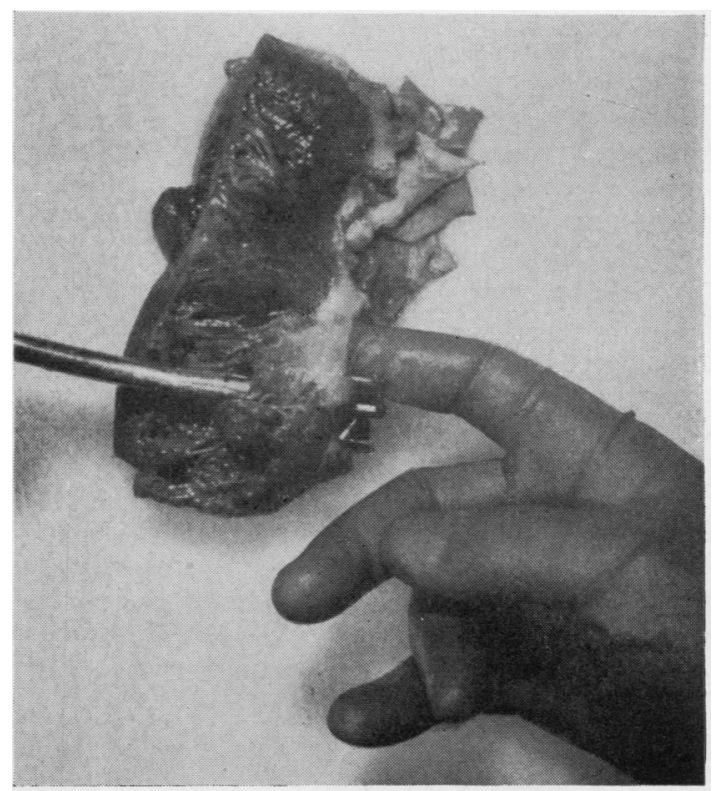

FIG. 4. A post-mortem heart with the dilator opened in the mitral valve and the index finger beside the dilator. 
T A B L E I

CLASSIFICATION OF 22 GRADE 3B PATIENTS SEEN EARLY AND LATE AFTER OPERATION

\begin{tabular}{c|c|c}
\hline Grade & Early Post-op. & Late Post-op. \\
\hline $3 \mathrm{~A}$ & 12 & 11 \\
2 & 8 & 8 \\
1 & 2 & 3 \\
\hline
\end{tabular}

T A B L E I I

CLASSIFICATION OF EIGHT GRADE 3A PATIENTS SEEN EARLY AND LATE AFTER OPERATION

\begin{tabular}{c|c|c}
\hline Grade & Early Post-op. & Late Post-op. \\
\hline 2 & 4 & 3 \\
1 & 4 & 5 \\
\hline
\end{tabular}

factory separation of the commissures was obtained, and at the conclusion the mitral incompetent jet was felt to be unchanged. At the end of operation a tracheostomy was performed, but the patient died 24 hours later with increasing cyanosis despite the assistance from intermittent positive pressure breathing. Post-mortem examination revealed a valve that was, technically, a satisfactory surgical result. The lungs showed the changes of pulmonary hypertension with wellmarked obstruction and obliteration of many of the smaller pulmonary arterioles. The second patient who died was a man aged 49 years. $\mathrm{He}$ had moderate mitral incompetence with a grade 3 mitral systolic murmur. The valve was moderately calcified, but a satisfactory split was obtained at operation with no increase in the mitral regurgitant jet. At the conclusion of operation a tracheostomy was performed. Over the next five days the patient gradually deteriorated with a low cardiac output state, progressive hypotension, and increasing cyanosis. In this case the mitral stenosis was possibly protective, and the relief of obstruction resulted in more serious mitral regurgitation which caused a fatal haemodynamic disturbance. Such a case would now be considered for total mitral valve replacement.

Two patients other than those referred to above had mild mitral incompetence before operation, and one other patient had moderately severe calcification of the valve. All of these patients had a satisfactory surgical result. In two patients a moderate amount of clot was present in the atrium which was extruded at the time of the atriotorny. Four of the patients had had previous valvotomies performed elsewhere, one patient having had two previous operations. One patient in the author's series had suffered a known further attack of rheumatic fever which eventually led to restenosis.
DISCUSSION

Although the trend in this unit is to operate on the mitral valve using cardio-pulmonary bypass for an increasing number of patients, it is felt that a place remains for the closed operation and that this is likely to be so for some time. We prefer closed mitral valvotomy for uncomplicated cases of mitral stenosis in normal rhythm who are under the age of 45 years. Men over the age of 45 who have their disease complicated by atrial fibrillation, emboli or calcification, are usually considered to be more suitable for operation using a cardiopulmonary bypass.

The two factors to consider in assessing the $\underset{\infty}{\mathscr{C}}$ effectiveness of this method are the clinical 을 improvement in the patient after operation and the presence of mitral incompetence. We have $>$ accepted clinical criteria for the evaluation of these results. Cardiac catheterization, which $\vec{\bullet}$ usually involves both right and left heart studies, of dye curves, and left ventricular angiocardiography, has been used on patients who had mitral valve disease when there was doubt as to the severity of the obstruction, when the lesion was mixed or when multivalve disease was present. We do not $\stackrel{\circ}{\circ}$ consider these investigations to be justified in a $\triangle$ patient who has had a successful operation and a $\overline{\mathrm{O}}$ satisfactory clinical result.

In the series reported by Logan and Turner in 1959 , in which 241 patients were operated on using a two-bladed trans-ventricular dilator, $19 \%$ were noted to be suffering from some mitral incompetence as judged by the presence of an apical ? systolic murmur appearing or increasing after $\frac{0}{3}$ operation. In this series the surgeon noted that instrumental injury to the mitral valve had occurred at operation in 15 patients, or $6.2 \%$. The operative injuries known to have been pro- $\frac{}{3}$ duced by the trans-ventricular dilator consisted $\rightarrow$ of either rupture of a chorda in two patients, detachment of the aortic cusp on six occasions, $N$ rupture of a mural cusp in four patients, and $N$ deviation of the line of commissural section $N$ around a sclerotic or calcific nodule in three $\mathrm{\omega}$ patients. Of the remaining $12 \%$ of patients in this series whose operation was complicated byc some mitral incompetence, no instrumental $\mathbb{D}$ damage was noted by the surgeon at operation and $\stackrel{?}{+}$ presumably the mitral incompetence that followed 0 operation was related to the degree of disease $\frac{O}{\mathbb{D}}$ rather than to the method of its relief. In a large $\stackrel{\odot}{\stackrel{P}{\oplus}}$ series of 1,009 patients operated on by Dubost $\mathbb{Q}$ (Dubost, Blondeau, and Piwnica, 1962) using a trans-atrial dilator, the production of traumatic $\delta$ 
insufficiency imputed to the use of the dilator is stated to be rare: but no exact figures to support this statement are given. A review of other series (Belcher, 1960 ; Gerbode, 1960 ; Brest, Uricchio, and Likoff, 1961; Harken, Black, Taylor, Thrower, and Ellis, 1961; and Morrow and Braunwald, 1961) suggests that the complication of serious or fatal mitral incompetence due to instrumental injury is uncommon.

In the present series the two deaths were not considered to be related to the method but were due to severe and complicated mitral valve disease. Although it is difficult to prove that one technique is superior to another, we suggest that a concentric expanding force exerted on a fused mitral valve is less likely to tear or damage the valve than a force that is exerted in two planes only by narrow blades. The advantage of our method is not only that the force is exerted over a large area ; but it is easy to control the force with the index finger in the atrium acting as a variable fourth blade.

\section{SUMMARY}

Thirty-two patients suffering from mitral stenosis are described. In these a three-bladed dilator has been used to carry out transventricular mitral valvotomy.

The principle of using the index finger in association with a three-bladed instrument is described.

The results in these patients are presented.

We wish to acknowledge the help given by our medical colleagues, and in particular Dr. Douglas Stuckey and Dr. R. G. Epps, who referred most of these patients for operation.

\section{REFERENCES}

Belcher, J. R. (1960). Restenosis of the mitral valve. Lancet, 1, 181.

Brest, A. N., Uricchio, J. F., and Likoff, W. (1961). Traumatic mitral insufficiency; a complication of mitral commissurotomy. J. Amer. med. Ass., 175, 1081.

Dubost, C., Blondeau, P., and Piwnica, A. (1962). Instrumental dilatation using the trans-atrial approach in the treatment of mitral stenosis-a survey of 1,000 cases. J. thorac. cardiovasc. Surg., 44, 392.

Gerbode, F. (1960). Transventricular mitral valvotomy. Circulation, 21,563 .

Harken, D. E., Black, H., Taylor, W. J., Thrower, W. B., and Ellis, L. B. (1961). Reoperation for mitral stenosis. Ibid., 23, 7.

Logan, A., and Turner, R. (1959). The surgical treatment of mitral stenosis. Lancet, 2, 874.

Morrow, A. G., and Braunwald, N. S. (1961). Transventricular mitral commissurotomy. J. thorac. Surg., 41, 225. 